$\begin{array}{ll}\text { Research Square } & \begin{array}{l}\text { Preprints are preliminary reports that have not undergone peer review. } \\ \text { They should not be considered conclusive, used to inform clinical practice, } \\ \text { or referenced by the media as validated information. }\end{array}\end{array}$

\title{
Examining Trust as a Key Determinant of eHealth Adoption in Malawi
}

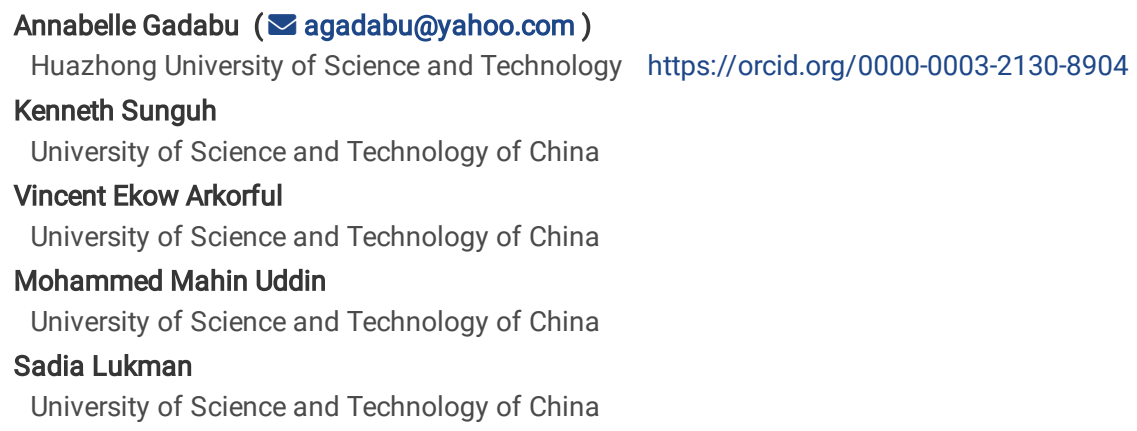

\section{Research article}

Keywords: eHealth, adoption, trust, Malawi, UTAUT, internet

Posted Date: November 15th, 2019

DOI: https://doi.org/10.21203/rs.2.17368/v1

License: (c) (i) This work is licensed under a Creative Commons Attribution 4.0 International License. Read Full License 


\section{Abstract}

The way technology is accepted and utilized may have significant hypothetical and concrete inferences. Thus, eHealth, like any other technology, has little value unless it is used. In this study, fundamental elements influencing consumers' decision to utilize eHealth services in Malawi were assessed. Using the Unified Theory of Acceptance and Use of Technology (UTAUT) model as the primary model of inference, two new constructs were introduced to determine whether trust is a significant contributor in consumers' decision to use eHealth. Through convenience sampling, a total of 400 responses were collected over a period of 6 weeks and evaluated using Structural Equation Modeling (SEM) technique. Outcomes of the analysis showed that Performance Expectancy, Effort Expectancy, Social Influence, and Facilitating Conditions, had an affirmative effect on Behavioral Intentions to use eHealth. Performance Expectancy indirectly had a positive effect on Behavioral Intentions to use eHealth services via Trust in internet and Trust in online healthcare providers. However, Trust of Internet had an insignificant effect while Trust in online healthcare providers had a positive effect. Thus, government and stakeholders in the health sector need to create platforms for engagement in health-related matters targeting the youth between 18 and 35 years who are the largest consumers of internet services.

\section{Introduction}

Society has transformed greatly since the dawn of modern computers with fast digitization and evolution in the amount of data created and shared (Kamkarian, 2016). Crucial to fiscal growth and development in the global economy, Information and Communication Technology (ICT) is highly relevant in the digital age (Milos Maryska, 2012).

As the Internet penetrated the public sphere throughout the 1990s, a number of e-terms such as e-government, e-learning, e-mail, e-banking, and e-commerce began to appear as well as proliferate offering new ways to conduct traditional tasks. The genesis of eHealth created an indispensable term and epitomized the potential for ICT to advance health and healthcare systems (Hans Oh, 2005).

Nkuzi (2014) asserts that as far as the health sector is concerned, eHealth helps minimize overheads providing enhanced patient-centered healthcare management (Nkuzi, 2014). It also saves time (Organization, 2015). Information can be shared securely and easily with colleagues and there is less paperwork for Doctors (Wass, 2017). Furthermore, people have more insight into their health through a personal digital healthcare environment (Services, 2006).

Regardless, eHealth implementation around the world is a challenge and chiefly in emerging countries (Ahmad B.I., 2014; Taylor, 2013), a mutual sentiment with the United Nations (UN) organizations and entities focusing on health from the global scene through to national scenes (Healy, 2008). Not only has implementation been a challenge but user acceptance has equally been difficult (Stegwee 2015; Venugopal 2016). With eHealth technologies becoming increasingly ubiquitous, research into determinants of effective recognition, reception, and utilization is equally becoming more important (Lankton, 2004; Calvin K.L. Or, 2011).

Generally, researchers have theorized technology acceptance as resulting from a psychological process that users experience in deciding to use technology (Morris, 2001). Hence, in an effort to explain technology acceptance, scholars have formed a number of models (Fishbein and Ajzen, 1975; Davis, 1989; Rogers, 1995; Venkatesh et al., 2003), with integrated versions (Caroline Lancelot Miltgen, 2013; Jorge Tavares, 2018) or extended versions (Carter, 2010; Ahmad Alaiad, 2014; Wilson-Evered 2012) over the years.

Low pace of adoption has been attributed to, among other things, consumer trust. Studies in other areas such as e-Government e.g. (Aubert, 2015; Murathan Kurfali, 2017) and e-Commerce (Pavlou, 2003; John, 2012) have demonstrated the importance of trust in electronic services adoption or impediment. This provides a basis for argument that this may apply to healthcare as well (Stegwee, 2015).

Multiple reports and studies advocate for the need for patient-centered healthcare and public policy is according increasing importance to consumer management of personal health (Services, 2006). Websites providing health services present an important opportunity to achieve this. As the internet becomes increasingly accessible and available to consumers through phones or computers, patient-centered healthcare becomes a greater possibility (Taylor, 2013). Nevertheless, use of the internet as opposed to traditional means of accessing healthcare remains in its infancy in Malawi.

Since the value of technology is in its use, the way it is accepted and used may have significant hypothetical and concrete inferences (Gunawardena, 2014). This study therefore utilizes the Unified Theory of Acceptance and Use of Technology (UTAUT) as the primary model with slight alterations, while employing Trust of Internet and Trust in Online Healthcare Providers as additional constructs assessing adoption of eHealth services among Malawian nationals. Considering the breadth of eHealth to include a vast array of services such as mobile health (mHealth), electronic health records, health knowledge management, health informatics, health research services tele-healthcare, and virtual healthcare (Malawi, 2014), this research centers particularly on the internet for healthcare provision as a form of eHealth. Results of the study will help create awareness among policy makers with reference to determinants of eHealth adoption and use. Relevant stakeholders will ultimately focus on increasing consumers' confidence in the ability of eHealth to accomplish their health needs.

Subsequent sections are organized as follows: first, the research problem and objectives are presented; secondly, a review of relevant literature is outlined highlighting a global outlook on eHealth, eHealth in Malawi, an overview of trust, and the UTAUT model; thirdly, the proposed model in this study and hypotheses are presented; following this is the study methodology; section six presents results of data analysis; section seven is a discussion of the results; and section eight concludes.

\section{Research Problem And Objectives}


This research proposes to examine the relationship between determinants of eHealth use and consumers' intention to use eHealth. What effects do Performance Expectancy (PE), Effort Expectancy (EE), Social Influence (SI), Facilitating Conditions (FC) and Trust in Internet (Tol), and Trust in Online Healthcare Providers $(\mathrm{ToH})$ have on behavioral intentions to use health-related websites? Similar to other information systems contexts, the study posits "consumers' trust in eHealth systems" as one of the fundamental enablers for adoption of eHealth. The study integrates trust with UTAUT model to examine user perception particularly towards health-related websites in Malawi. By examining the above mentioned relationship, it is anticipated that the study will uncover some fundamental contributors to adoption, or lack thereof, of eHealth and provide solutions to ensuring greater inclusion of consumers in future eHealth policy development.

\section{Literature Review}

\subsection{Global outlook on eHealth}

Through resolution WHA58.28 (2005), the World Health Organization (WHO) encourages countries to incorporate ICT into health service delivery. Focusing its efforts principally in countries in transition as well as developing countries, WHO is playing a principal role in modeling and observing the future of eHealth. It has also become increasingly clear that the role of eHealth is crucial to achieving Universal Health Coverage (UHC). In September 2015, the UN General Assembly endorsed the Sustainable Development Goals (SDGs). Goal 3 aims to "ensure healthy lives and promote well-being for all at all ages" and target number 8 under Goal 3 aims to achieve UHC in order to provide all people with high-quality services "without suffering financial hardship". E-health is therefore in a position to enhance integrated, people-centered health service and support an all-inclusive and comprehensible approach to health (Organization, 2012).

Resolution AFR/RC56/ R8,7 called for UN countries to embrace, develop, and implement policies on eHealth to develop their health sectors. Furthermore, the Ouagadougou8 and Algiers declarations also underscore eHealth as significant to health systems strengthening (Kebede, 2014). Today, eHealth strategies exist in over $50 \%$ of WHO Member States, and $90 \%$ of eHealth strategies recognize the achievement of UHC as a vital objective (Organization, 2012).

Regardless, implementation and adoption of eHealth has been a mixed bag of successes and failures. In reviewing some country experiences with eHealth, Denmark is often referred to as an outstanding example of digital health implementation amongst developed countries with a robust eHealth system.

Singapore, a country in transition, has also registered positive results and is developing a robust National Electronic Health Record (NEHR) system. In contrast, the United Kingdom's National Programme for IT in the National Health Service (NPfIT) was not so successful and consequently the program was dismantled in 2011 (Authority, 2016).

In a study profiling eHealth projects in Africa, Taylor et al. (2013) found that all four regions of the continent are characterized by countries which are highly involved in eHealth programs. For instance, in northern Africa, Tunisia, Algeria, Egypt, and Morocco; in Eastern Africa, Tanzania, Rwanda, Ethiopia, Uganda, Madagascar, Kenya, Zambia Malawi, and Mozambique; in Southern Africa, Zimbabwe and South Africa; and in Western Africa, Nigeria, Senegal, Mali, Ghana, Burkina Faso, The Gambia, Ivory Coast, and Sierra Leone (Taylor, 2013). It is mostly Governments of high income countries that are funding eHealth projects from inception in African countries with very few projects funded by the Ministries of Health. This might have provided an impetus for host countries to support national initiatives. Nevertheless, when donor funding is exhausted projects have mostly ceased because of lack of scalability and sustainability (Molefi, 2010).

The successes and failures of eHealth implementation within countries has been attributed to governance structures and policy frameworks. Moreover, incountry health systems, telecommunications, stakeholder diversity, and social safety nets have also been key factors in determining success or failure (Authority, 2016). A classic source of difficulties in eHealth implementation has been with the tendency to copy wholesale projects from wealthy countries and assume they will work in low-income countries as well. Researchers therefore conclude advise that eHealth services should be introduced based on an assessment of local settings and respond to particular requirements utilizing ICTs (Union I. T., 2008).

\subsection{E-health adoption in Malawi}

According to Bichler (2008), Malawi had its initial link to the internet in 1993 (Bichler, 2008). Kankuzi (2008) adds that the connection was through the Department of Physics at Chancellor College, and over time, the approval of the internet significantly weakened utilization of competing networks such as FidoNet (Kankuzi, 2008).

Results of a visibility study undertaken by the United Nations Development Programme (UNDP) in 1995 indicated that a market existed for internet. In 1997, the private company Malawi Net was licensed as the first Internet Service Provider (ISP) (Bichler, 2008). New private ISPs such as Africa-online, Globe Internet Company, and Malawi Telecommunications Limited (MTL) (Kankuzi, 2008).

Seeing the potential for ICT to transform the health sector, government of Malawi (GoM) since 2002, has implemented various initiatives aimed at supporting national Health Management Information Systems (HMIS) Firstly, government implemented the District Health Information Systems (DHIS2) which is the central data repository (Chikumba, 2017). A situation analysis highlighted the availability of electronic medical records (EMR) systems in several district hospitals, even though attention is paid to particular illnesses and therefore departments (Malawi, 2014). Secondly, in 2013, the Health Information Systems (HIS) strategy was developed to ensure an adequate provision of information support to stakeholders in making decisions based on empirical evidence for health services planning and administration (Malawi, 2015).

Thirdly, GoM introduced the national eHealth Strategy in 2014 (Malawi, 2014) in line with WHO recommendations (Organization, 2012). The Malawi National E-Health Strategy envisions an integrated eHealth resolution that enhances lives in the delivery of health services through: 
1. Laying foundations for ICT infrastructure by identifying national connectivity services, eHealth information standards, computing, infrastructure, reliable power supply, and information protection.

2. Electronic interaction with the health system through tele-healthcare, individual electronic health records, and continuous professional care.

3. Increased engagement in eHealth education and training, and awareness campaigns.

4. Consultative meetings with relevant committees such as the eHealth Strategy steering committee and the stakeholders' consultation forums and working groups (Malawi, 2014).

Furthermore, mHealth projects in Malawi have existed since at least 2007, with an average of 2 new projects coming online each year (Cooper/Smith, 2018). With mobile phones becoming a universal fixture globally and more so in countries like Malawi where more than $85 \%$ of households own a phone, it is hardly astounding that the health sector in Malawi is seeing a large influx of mHealth projects as a means of reaching the population for healthcare delivery, data collection, and supervision (Fletcher, 2018). In 2017, the Secretary for Health and Population required that all Malawian mHealth projects complete a formal registration process. $31 \mathrm{mHealth}$ projects officially registered (Cooper/Smith, 2018)

In order to move towards achieving Universal Health Coverage (UHC) of quality, equitable and affordable healthcare (Malawi, 2017), Malawi is making strides to develop a robust electronic health system (Malawi, 2014).

\subsection{Trust}

Owing to the vital societal role that trust plays, it is therefore researched extensively by scholars in several areas of research. Consequently, trust theory suffers from a myriad of theories, notions (Joana Urbano, 2012), complexities, and multiple facets making it difficult to measure, construe, and operationalize (Simpson, 2007). In trust literature, a recurrent misconstruction concerns the distinction and relation between trust and trustworthiness (Joana Urbano, 2012).

Personality theorists view trust as a credence, an anticipation, or sentiment profoundly embedded in an individual's personality (Cheung \& Lee, 2006). Thus, with reference to the trustor, trust is viewed as a characteristic that leads to a generalized anticipation about the trustworthiness of others (Roger $\mathrm{C}$. Mayer, 1995). In contrast to personality psychologists, social psychologists regularly conceptualize trust to be a person's mental state at a particular time influenced mainly by contextual factors (Weitzl, 2017).

Trustworthiness, on the other hand, is a feature in the article of the trustors attitude that fulfills it and assists in making it applicable. In other words, it is that feature offering adequate cause to merit a trusting attitude (Philip J. Nickel, 2010). Weiner's (1986) causal attribution theory aids understanding the progressions that occur in updating perceptions of trustworthiness, thus contributing new insights into how trust is damaged and repaired (Tomlinson, 2009). Mayer et al. suggest that in a relationship with a definite other party, perceptions of three characteristics of the party will govern the trustor's consideration of the party's trustworthiness.

- Ability: the degree to which the party is believed to have skills and abilities in the trustor's sphere of interest

- Benevolence: the degree to which the party is thought to aspire to do act affirmatively for the trustor

- Integrity: this is when the party observes certain standards satisfactory to the trustor.

High instance of these three factors will lead to trust and after risking an encounter with the trustee, the trustor will assess the results (Tomlinson, 2009). If a trustee is deemed as high on all three factors, it is argued here that the trustee will be perceived as quite trustworthy (Roger C. Mayer, 1995).

Trust in technology, however, is a contentious matter in the literature. For instance, Philip J. Nickel et al. (2010) argue that since the factors that motivationattributing accounts of trust present are qualities which only humans generally hold, it is therefore sensible to determine that trustworthiness does not genuinely apply to technology; but rather that technology is reliable (Philip J. Nickel, 2010). On the contrary, others like Wallace et al. (2003) theorize that since computer technology has the ability to mimic human behaviours and accomplish roles humans conventionally employ, this changes our limited perspective of it as simply being an accessory to being more of a social companion. Therefore, a suitable architype vis a vis human to computer interface concerns the human to human relational exchanges. Therefore, there seems to be satisfactory proof confirming people's are ability to instill trust in technology for instance, trust placed in a computer system or information document (Wallace, 2003). Furthermore, scholars affirm that consumer attitudes to technology, and particularly trust, has an effect on how that technology is used (Pavlou, 2003; John, 2012; Aubert, 2015; Kurfali, 2017).

Trust is critical in healthcare relationships since a patient trusts their healthcare provider for quality care in a timely fashion; healthcare providers trust that patients will divulge accurate personal health information; and healthcare providers trust one another to provide the best possible healthcare to patients. Growing internet use creates another facet to these relationships (Laurian C. Vega, 2011). In recent years, trust has captured the devotion of website designers that focus on providing medical information for some obvious reasons (John M. Blythe, 2017). Since health is a highly personal aspect of life, it is necessary to evaluate the technology comprehensively to enhance adoption and utilization and this evaluation relatively involves trust. Basically, research into trust in eHealth is actually an investigation into the association between individuals and technology (Laurian C. Vega, 2011).

Tan and Theon argue there are two objectives to trust in technology; one objective is service provider offering services, the other objective is the device bridging the service provider and consumer (Theon, 2001). Carter and Belanger (2005) also stress that trust in technology falls between two facts which are trust of service provider and trust of the mechanism with which the service is made available which is the internet (Belanger, 2005). Nickel et al. (2010) share the same sentiments and state that when it comes socio-technical systems involving control by humans, it is not sensible that trust placed on those controlling the system should be directly placed on the entire system (Philip J. Nickel, 2010). 
Thus, in this paper, trust is presented along these lines (Theon et al. 2001; Nickel et al. 2010; Carter and Belanger, 2005) distinguishing between trust in internet as a mechanism and trust in vendor which is conceptualized as trust in online healthcare service providers. This does not mean that trust is a solution for all adoption matters. Trust is an essential prerequisite but not an adequate prerequisite for user adoption. Indeed, trust is only a first step and an essential prerequisite (Stegwee, 2015) as trust beliefs may lead to intentions, and intentions may lead to behavior (H. Alsaghier, 2009). While it is important that believing an online service is trustworthy, it does not lead to automatic adoption of the service (Stegwee, 2015). After all, as demonstrated by the UTAUT model, other factors influence adoption as well (Venkatesh, 2013).

\subsection{Unified Theory of Acceptance and Use of Technology (UTAUT)}

The success or failure of technology-based projects highly depends on consumer attitudes to utilization and adoption. Venkatesh et al., theorize technology acceptance as the "an individual's preliminary decision to relate to the technology" (Venkatesh, 2013). By means of theories that investigate what hinders acceptance and promote usage of technologies, individual user acceptance of technology has been modeled and predicted (Gunawardena, 2014).

Venkatesh, Morris, and Davis (2003) studied from prior models/theories and formed UTAUT (Gunawardena, 2014). Some of the prior theories are: Theory of Reasoned Action (TRA) (Fishbein and Ajzen, 1975); Expectation-Disconfirmation Theory (EDT) (Oliver, 1980); Social Cognitive Theory (SCT) (Bandura, 1986); Technology Acceptance Models (TAM) (Davis, 1989; Davis et al., 1989); Theory of Planned Behavior (TPB) (Ajzen, 1991); Model of PC Utilization (MPCU) (Thompson, Higgins, and Howell, 1991); the Motivational Model (MM) (Davis, Bagozzi, \& Warsaw, 1992); Innovation Diffusion Theory (IDT) (Rogers, 1995); Task Technology Fit Model (TTF) (Goodhue and Thompson, 1995); and Decomposed Theory of Planned Behavior (DTPB) (Taylor and Todd, 1995) (Gunawardena, 2014).

The UTAUT proposes Performance Expectancy, Effort Expectancy, Social Influence, and Facilitating Conditions as determinants for behavioral intention (Lai, 2017). The model also includes Gender, Age, Experience, and Voluntariness of Use as moderators. (Ahmad M. I., 2015). By comparing prevailing theories and models Gunawardena et al. (2014) highlight the superiority of the UTAUT in explaining user acceptance and use of technology. Firstly, UTAUT presents conditional variables such as Age, Gender, Voluntariness of Use, and Experience which add vital situational information although the primary constructs are crucial to explaining the technology acceptance and use (Gunawardena, 2014).

Based on extensive literature review, Kripanont (2007) and Venkatesh et al. (2003) have also compared nine models to demonstrate specific models' explanatory power in relation to behavioral intentions. Findings indicate that in terms of variance (variance $\mathrm{R}^{2}$ ), the strength of different models to explain intentions has resulted in a lowest score of 0.36 (Theory of Reasoned Action; Social Cognitive Theory) to the highest score of 0.69 (UTAUT). This therefore indicates the powerful explanatory ability of the UTAUT in relation to determinants of behavioral intentions. The UTAUT adds an enhanced comprehension of the determinants of acceptance and use of novel technologies compared to related theories and models (Gunawardena, 2014). The following section highlights the proposed model which excludes moderating factors while introducing two new constructs related to trust.

\section{Theoretical Model}

The UTAUT is the primary model for this research but with several alterations. Behavioral Intention to Use eHealth services (BI) is the dependent variable. Performance Expectancy (PE), Effort Expectancy (EE), Social Influence (SI), and Facilitating Conditions (FC) are maintained as independent variables. However, three moderators including Gender, Age, Experience and Voluntariness of use are excluded from the model as moderators and are neither used as control variables. Two constructs of trust are added to the original UTAUT model including Trust in Internet and Trust in Online Healthcare Providers. Specific details of the model and hypotheses are subsequently presented.

\section{a Behavioral intention to use (BI)}

Developed by Fishbein and Ajzen (1975), the Theory of Reasoned Action suggests that certain underlying beliefs about the probability of a specific behavior to result in particular outcomes will lead to behavioral intentions. Proposed by Ajzen (1985), the theory of planned behavior adds perceived behavioral control as an extrinsic variable affecting behavior directly and indirectly via intentions (Thomas J. Madden, 2014). Nevertheless, researchers have proven that behavioral intention to use and concrete technology usage are related. Thus, they propose that combining behavioral intention and use behavior to form "behavioral intention to use" makes sense (Mohammed Alshehri, 2013). Therefore, "behavioral intention to use" is used in this research as the dependent variable to demonstrate the concrete usage of eHealth services.

\section{b Performance Expectancy (PE)}

PE is "the extent to which an individual believes that utilizing the technology will assist him or her to realize benefits in job performance" (Ahmad M. I., 2015). The value of an eHealth service is in the degree to which the facility affords a meaningful contribution to a patient's health. After all, perceived usefulness is a major part of trust and in this case health related usefulness. Thus, it is expected that an effective eHealth service will provide a healthier balance between outcome and effort required (Stegwee, 2015). Consumers' positive attitude toward eHealth's ability to attain intended healthcare objectives can stimulate adoption. Therefore, we posit that:

Hypothesis 1: Performance expectancy will positively affect behavioral intention to use ehealth services 


\section{c Effort Expectancy (EE)}

Effort Expectancy is "the extent of ease related to the system use" (Ahmad M. I., 2015). High ease of use is fundamental to effort expectancy and relates to how easily users can navigate a technological platform. For instance, how easily one can navigate an eHealth website. Difficulties in finding information due to vaguely structured menus and web pages means a waste of time and is one of the major risk factors for eHealth. This suggests that a user-friendly and navigable structure should supersede improved visual appeal. Then again, if the visual appearance decreases significantly, this may also decrease trust in the service (Stegwee, 2015). Thus, the assumption here is that the more user-friendly, expedient, and easy-to-use the technology is, the greater the likelihood that consumers will intend to use the service. Therefore, we posit the following:

\section{Hypothesis 2: Effort expectancy will have a positively affect behavioral intentions to use eHealth services}

\section{$d$ Social Influence}

Social influence is "the extent to which an individual perceives that important others believe he or she should use the new system". It is dependent on an extensive range of provisional stimuli with three mechanisms affecting individual behavior namely; compliance, internalization, and identification. Varying individual's intention in reaction to societal forces is a function of compliance mechanism while the latter two mechanisms concern altering and amending an individual's beliefs structure and/or initiating the individual's reaction to possible situational benefits. Thus, adoption or resistance to change me be as a result of stimulus from associates. (Ahmad M. I., 2015). This study posits that:

\section{Hypothesis 3: Social Influence will positively affect behavioral intentions to use e-health services}

\section{e Facilitating Conditions}

Facilitating Conditions is "the extent of belief an individual holds in the existence of an organizational and technical infrastructure to facilitate system use". It combines three key variables derived from preceding theories: firstly, perceived behavioral control which is individual insight into the existence or lack of necessary means and prospects; facilitating conditions defined as impartial environmental features that participants approve enable easy accomplishment of an act; and compatibility defined as the extent to which a novelty is observed to be well-suited to prospective users' prevailing standards, desires, and previous involvements" (Ahmad M. I., 2015). The study therefore examines how facilitating conditions affect intention to use. The following is therefore hypothesized:

\section{Hypothesis 4: Facilitating conditions will positively affect behavioral intentions to use eHealth services}

\section{f Trust in internet (Tol)}

With reference to trust in internet, the expectation is that there should be minimal or no technical errors (Stegwee, 2015). Reliability of technical artifacts is often deemed to be a preferable feature (Philip J. Nickel, 2010). Thus in this case, technical reliability relates to whether the service will experience a systems fault or other failures. Ossebard et al. (2012) have identified technical failures as a significant risk for Dutch eHealth adoption, as they may lead to higher time consumption and higher costs (Stegwee, 2015). Thus, in this study, we propose that the degree with which an individual has confidence in the benefits which using the technical artifact will provide positively affects their belief in the reliability of the technical artifact. Therefore, we posit the following:

\section{Hypothesis 5: Performance expectancy positively affects Trust of internet}

With reference to e-Government, Kurfali et al. (2017) theorized that trusting beliefs in the internet will positively affect behavioral intentions. This paper explores this relationship with reference to eHealth. Thus, we posit the following:

\section{Hypothesis 6: Trust of internet positively affects behavioral intentions to use eHealth services}

\section{g Trust in online healthcare providers (ToH)}

Tomlinson (2009) defines benevolence as the degree to which the object warranting an attitude of trust, which is the trustee, is thought to have good intentions towards the trustor. It concerns the trustors assessment of the trustee's good intentions (Tomlinson, 2009). Illustrations of this will frequently relate to privacy issues such as providers' intentions when handling patient data for purposes the patient is inadequately aware of. In this case, the trustee is not the eHealth system itself because technology cannot have its own intentions. Therefore, this domain applies to the providers of the eHealth services such as technology developers and the healthcare institution (Stegwee, 2015). In this study it is theorized that consumers' positive attitude toward eHealth's ability to attain intended healthcare objectives will positively affect their trust in online healthcare service providers. The following is therefore posited:

\section{Hypothesis 7: Performance expectancy will positively affect Trust of online ehealth service providers}

Kurfali et al. (2017) hypothesized that trust in government will positively affect behavioral intentions. However, results of the analysis of this relationship found that this relationship was not significant and therefore not supported. This paper explores this relationship in the context of eHealth and hypothesizes 
the following:

Hypothesis 8: Trust of online ehealth service providers will positively affect intentions to use ehealth services

Figure 1: Proposed research model

\section{Methodology}

\subsection{Study design}

The study employed a quantitative approach and engaged in hypotheses testing. It was a correlational study since it endeavored to understand if a link exists amongst the examined variables thus validating the relationship. To attain the research objectives, a model was formulated after a comprehensive literature review. UTAUT is the selected model with several adaptations to suit the research context.

\subsection{Instrument development}

The research questionnaire contained items primarily adopted from previous studies, while integrating the necessary authentication and phraseology in order to adapt it to the research context. Venkatesh et al. (2003) was used as a reference point for adapting items measuring PE, EE, SI, and FC. Items measuring Tol and ToH were adapted from (Murathan Kurfali, 2017). All questions were rated on a five-point Likert-type scale spanning from "Strongly Agree" to "Strongly Disagree." Questions were clear and simple, intended to find out respondents' general attitude towards eHealth. The questions further sought to capture respondents' prospects of using eHealth services in the near future. Respondents' gender, age, occupation and education information was also collected.

The questionnaire was presented to two PhD students who have knowledge in the area. Thereafter, a pretest was carried with 20 respondents to ensure content validity. The data was then examined for completeness of responses, reviewed and modified in accordance with recommendations. To ascertain questionnaire reliability Cronbach Alpha analysis was conducted.

\subsection{Sampling}

A sample of Malawian citizens who use the internet was identified for this study. Sampling is a method of choosing an adequate proportion of components out of the population. If the right sample is selected It is promising to apply features of the components to the population elements (Sekaran, 2003). Convenience sampling was used because it is quick, inexpensive, and convenient since researchers simply use participants who are available at that particular moment (UCA, 2018).

According to preliminary results of the Malawi National Statistical Office (NSO) census conducted by the in 2018, the current population of Malawi is $17,563,749$ (Office, 2018). Estimates indicate that only $9.61 \%$ of Malawians have access to internet (Stats, 2018). This translates to $1,687,876$ internet users. Thus, with reference to Dessel's (2013) suggestion on the appropriate size of a sample, at a confidence level of $95 \%$ and a margin of error of $5 \%$, an approximate sample of 350 complete responses was required (Dessel, 2013).

The survey focused on individuals aged over 18 years as they are likely to have means of accessing the internet, have the interest to access internet, and have better familiarity with internet-based services (Bansal, 2016). Consequently, the probability that the young adult and older age groups in the population will use eHealth services is higher compared to those below 18 years.

\subsection{Data Collection}

The study adopted a cross-sectional approach to data collection in which data was collected at once for 6 weeks. Online survey was the chosen method of data collection because it is a cost and time efficient method. A questionnaire was developed on www.wjx.com. A questionnaire link was then sent through email and social media groups on Facebook, Linkedln, Twitter, WhatsApp, and WeChat. A total of 400 responses were collected from 198 males and 202 females. No incentives were provided to respondents due to financial reasons as well as to avoid bias in response.

\section{Analysis And Results}

\subsection{Statistical analysis}

Analysis was done using Structural Equation Modeling (SEM). SEM comprises several set multivariate processes such as regression analysis, discriminant analysis, canonical correlation, and factor analysis. SEM therefore provides a broad and appropriate context for analysis executed statistically. Secondly, SEM is suitable for analyzing hypothetical concepts that are characterized by latent factors (Bechger, 2003) as is the case with this study.

Firstly, using SPSS 21.0, demographic data was analyzed. subsequent analysis involved a reliability test to

determine whether measurements were consistent. Using Lisrel 8.7 statistical software, Structural Equation Modeling was performed involving convergent and discriminant validity to determine construct validity, model testing, and hypothesis testing. The subsequent section provides details of the analysis and results. 


\subsection{Reliability test}

A Cronbach Alpha test suggests four cut-off points that represent results ranging from excellent to low (Murathan Kurfali, 2017). Results of the Cronbach analysis (Table 2) indicate that 6 constructs have excellent reliability represented by scores above 0.90 while 1 construct has high reliability represented by a score above 0.70 indicating that items representing the same construct are internally reliable.

\subsection{Construct validity analysis}

For two reasons, Confirmatory factory analysis (CFA) is done. Firstly, it is done to realize approximations of the model framework, that is, the factor variances and co-variances, the residual error variances of the observed variables, and the factor loadings. Secondly, it is done to see if the model is a good fit to the data (Bechger, 2003).

This process required firstly, a convergent validity test which was applied by means of composite reliability (CR) average variance extracted (AVE). Results show all CR scores above 0.7 indicating sufficient representation of proposed constructs with respect to primary constructs (Binesh et al, 2018; Murathan Kurfali, 2017). Outcomes of AVE indicated scores higher than the recommended 0.5 score (Bansal, 2016). This means the questionnaire had good convergent validity (Binesh Sarwar, 2018). Results are presented Table 2.

Secondly, discriminant validity test was applied by using AVE and it is confirmed when there is low correlation between a measure and another measure which it ought to be different (Binesh Sarwar, 2018). Thus, Table 3 shows the scores of square roots of AVE in bold diagonal cells higher than correlations between constructs thus indicating a good discriminant validity (Bansal, 2016; Binesh et al., 2018). 
Table 2: Result of Confirmatory Factor Analysis (CFA), Composite Reliability (CR), and Average Variance Extracted (AVE).

\begin{tabular}{|c|c|c|c|c|}
\hline Constructs & Factor loading & Cronbach's alpha & CR & AVE \\
\hline \multicolumn{2}{|c|}{ Performance Expectancy } & .912 & .911 & .774 \\
\hline PEl1 & .842 & & & \\
\hline PEI2 & .989 & & & \\
\hline PEI3 & .796 & & & \\
\hline \multicolumn{2}{|c|}{ Effort Expectancy } & .950 & .950 & .826 \\
\hline EE1 & .967 & & & \\
\hline EE2 & .823 & & & \\
\hline EE3 & .993 & & & \\
\hline EE4 & .840 & & & \\
\hline \multicolumn{2}{|c|}{ Social influence } & .929 & .926 & .862 \\
\hline SI1 & .923 & & & \\
\hline $\mathrm{SI} 2$ & .933 & & & \\
\hline \multicolumn{2}{|c|}{ Facilitating Conditions } & .886 & .895 & .811 \\
\hline FC1 & .987 & & & \\
\hline FC2 & .804 & & & \\
\hline \multicolumn{2}{|c|}{ Trust in Online Health providers } & .919 & .914 & .779 \\
\hline TH1 & .894 & & & \\
\hline TH2 & .863 & & & \\
\hline TH3 & .890 & & & \\
\hline \multicolumn{2}{|c|}{ Trust in internet } & .957 & .955 & .754 \\
\hline TI1 & .768 & & & \\
\hline $\mathrm{TI} 2$ & .991 & & & \\
\hline TI3 & .805 & & & \\
\hline TI4 & .986 & & & \\
\hline TI5 & .782 & & & \\
\hline TI6 & .805 & & & \\
\hline TI7 & .908 & & & \\
\hline \multicolumn{2}{|c|}{ Behavioral intentions } & .902 & .898 & .747 \\
\hline Bl1 & .810 & & & \\
\hline $\mathrm{BI} 2$ & .904 & & & \\
\hline $\mathrm{BI} 3$ & .876 & & & \\
\hline
\end{tabular}

Extraction Method: Maximum Likelihood, Rotation Method; Promax with Kaiser Normalization 
Table 3. Descriptive Statistics, Correlation Matrix, Reliability, and Square Root of AVE.

\begin{tabular}{|c|c|c|c|c|c|c|c|c|c|c|}
\hline Sr. & Construct & $M$ & (SD) & 1 & 2 & 3 & 4 & 5 & 6 & 7 \\
\hline 1. & Performance Expectancy & 1.91 & $(0.81)$ & 0.880 & & & & & & \\
\hline 2. & Effort Expectancy & 1.88 & $(0.77)$ & 0.430 & 0.909 & & & & & \\
\hline 3. & Social Influence & 2.33 & $(1.07)$ & 0.369 & 0.441 & 0.928 & & & & \\
\hline 4. & Facilitating Conditions & 1.84 & $(0.77)$ & 0.247 & 0.318 & 0.289 & 0.901 & & & \\
\hline 5. & Trust in Health Providers & 2.07 & $(0.89)$ & 0.322 & 0.411 & 0.496 & 0.253 & 0.983 & & \\
\hline 6. & Trust in Internet & 1.90 & $(0.83)$ & 0.499 & 0.444 & 0.482 & 0.282 & 0.496 & 0.868 & \\
\hline 7. & Behavioral Intentions & 1.85 & $(0.78)$ & 0.445 & 0.477 & 0.408 & 0.346 & 0.379 & 0.427 & 0.864 \\
\hline
\end{tabular}

$\mathrm{M}$ - Mean; SD - Standard deviation. Note. $\mathrm{N}=400$. All correlations are significant at $\mathrm{p}<0.001$. Bold values on the diagonal represent square root of average variance extracted (AVE).

\subsection{Descriptive statistics}

Table 4 indicates relatively fair response from both males and females with $50.5 \%$ of respondents being female. Over $70 \%$ are aged below 35 years supporting observations by Binesh et al. (2018) stating that 93\% of people between 18 and 29 years are the largest internet and social network users (Binesh Sarwar, 2018). A large number of respondents also possess one or the other of a first degree or second degree. $54 \%$ of respondents are employed either on a full time or part-time basis while $24.8 \%$ indicated belonging to the "Other" category. This could possibly capture students which was not a category specified as an occupation. Nevertheless, this provides good insights into those who are using the internet the most. Interestingly, over $74.8 \%$ of respondents showed over 5 years of internet use and $82.3 \%$ use it on a daily basis. This shows that the majority have experience using internet. 
Table 4: Descriptive statistics

\begin{tabular}{lll} 
Demographics & Frequency & Percentage \\
\hline Gender & & \\
\hline Male & 198 & $49.5 \%$ \\
\hline Female & 202 & $50.5 \%$ \\
\hline Age & & \\
\hline $18-25$ & 110 & $27.5 \%$ \\
\hline $26-35$ & 174 & $43.5 \%$ \\
\hline $36-45$ & 65 & $16.3 \%$ \\
\hline $46-59$ & 36 & $9.0 \%$ \\
\hline $60+$ & 15 & $3.8 \%$ \\
\hline
\end{tabular}

\begin{tabular}{lll}
\hline Level of education & & \\
\hline Secondary Certificate & 36 & $9.0 \%$ \\
\hline Professional Diploma & 64 & $16.0 \%$ \\
\hline Bachelor's degree & 151 & $37.8 \%$ \\
\hline Master's degree & 114 & $28.5 \%$ \\
\hline Doctorate & 30 & $7.5 \%$ \\
\hline Other & 5 & $1.3 \%$ \\
\hline
\end{tabular}

Occupation

\begin{tabular}{lll}
\hline Unemployed & 62 & $15.5 \%$ \\
\hline Intern & 23 & $5.8 \%$ \\
\hline Part-time worker & 46 & $11.5 \%$ \\
\hline Full-time worker & 170 & $42.5 \%$ \\
\hline Other & 99 & $24.8 \%$
\end{tabular}

Internet experience

\begin{tabular}{lll}
\hline $0-6$ months & 1 & $0.3 \%$ \\
\hline $7-12$ months & 11 & $2.8 \%$ \\
\hline $1-4$ years & 89 & $22.3 \%$ \\
\hline $5+$ years & 299 & $74.8 \%$ \\
\hline
\end{tabular}

\begin{tabular}{lll}
\hline Intemet use frequency & & \\
\hline once a month & 3 & $0.8 \%$ \\
\hline once a week & 7 & $1.8 \%$ \\
\hline a few times a week & 61 & $15.3 \%$ \\
\hline every day & 329 & $82.3 \%$ \\
\hline
\end{tabular}

\subsection{Model fit testing}

Model fit testing was carried out for both the Measurement Model and the Structural Model. Bechger (2003) asserts that all goodness-of-fit measures are some function of the degrees of freedom (df) and the chi-square $\left(\mathbb{\nabla}^{2}\right)$ (Bechger, 2003). The chi-square values were 427.45 and 613.01 while the degrees of freedom were 231 and 238 respectively. However, scholars argue that adjusted $\rrbracket^{2}$ ( $\rrbracket^{2} /$ degrees of freedom) is an appropriate metric as $\mathbb{\bigotimes}^{2}$ alone is not strong for 
sample size (Murathan Kurfali, 2017). Analysis of fitness indices such as Goodness of Fit Index (GFI), Adjusted Goodness of Fit Index (AGFI), Root Mean Square Error of Approximation (RMSEA), Comparative Fit Index (CFI), Incremental Fit Index (IFI), and Normed Fit Index (NFI) were applied. These indices are reported in line with previous research (Belanger, 2005; Kurfali, 2017; Binesh et al. 2018). Recommended values and outcomes of the overall measurement model fit and structural model fit tests are presented in Table 5 and Table 6 respectively.

Table 5: Goodness of Fit statistics for Measurement Model

$\begin{array}{llllllllll}\text { Model } & X^{2} & \text { df } & X^{2} / \mathrm{df} & \text { GFI } & \text { AGFI } & \text { RMSEA } & \text { CFI } & \text { IFI } & \text { NFI } \\ \text { Range } & - & - & <3.00 & >0.8 & >0.80 & <0.08 & >0.9 & >0.9 & >0.9 \\ \text { Base } & 427.45 & 231 & 1.850 & 0.92 & 0.89 & 0.046 & 0.99 & 0.99 & 0.98\end{array}$

Table 6: Goodness of Fit statistics for Structural Model

\begin{tabular}{llllllllll}
\hline Model & $\mathrm{X}^{2}$ & $\mathrm{df}$ & $\mathrm{X}^{2} / \mathrm{df}$ & $\mathrm{GFI}$ & $\mathrm{AGFI}$ & $\mathrm{RMSEA}$ & $\mathrm{CFI}$ & $\mathrm{IFI}$ & $\mathrm{NFI}$ \\
\hline Range & - & - & $<3.00$ & $>0.8$ & $>0.80$ & $<0.08$ & $>0.9$ & $>0.9$ & $>0.9$ \\
\hline Base & 613.01 & 238 & 2.576 & 0.89 & 0.86 & 0.063 & 0.98 & 0.98 & 0.97
\end{tabular}

\subsection{Hypothesis testing}

Subsequent to model fit testing, hypothesis testing was conducted. The results indicate that all but one of the constructs (H6) are significant predictors of consumer choice of adopt and use of eHealth services. The research model also endeavored explored the link between PE and Tol (H5) as well as PE and ToH $(H 7)$. $\mathrm{H} 5$ indicates greatest significance $(\beta=0.55, p<0.001)$; that means, consumers have a higher expectation of the internet to perform well in order to also be able to trust that eHealth services will accomplish its purpose. Furthermore, $\mathrm{H} 7$ indicates a high $(\beta=0.39, \mathrm{p}<0.001)$ meaning that consumers' expectations for Online Healthcare Providers to offer reliable, safe, and healthcare services is significant and this influences their level of trust in their decision to use eHealth services.

\section{Figure 2: Results of hypothesis testing}

\section{Discussion}

Founded on the UTAUT model, the model used in this research examined determinants of consumer use of eHealth with an extension of Trust in Internet and Trust in Online Healthcare Providers added to the model. Considering the breadth of eHealth to include services such as; mobile health (mHealth), electronic health records, health knowledge management, health informatics, tele-healthcare, virtual healthcare, and health research services (Malawi, 2014), this study focused particularly on internet use for delivery of healthcare services as a form of eHealth.

Since 1969 the internet has existed. But with the revolutionary discovery of the World Wide Web in 1991, accessibility of the internet became more widespread. Today, the internet is a global platform (Kamkarian, 2016) and a universal feature in the home, the school, and in the workplace reaching a worldwide user population of over 400 million (Weiser, 2002). This study therefore provided valuable insights into underlying determinants of consumer decision to adopt eHealth services in Malawi particularly through the internet.

All four of the factors in the UTAUT model including: effort expectancy (EE), performance expectancy (PE), facilitating conditions (FC), and social influence (SI) positively affect behavioral intention. New hypotheses are introduced into the model $(\mathrm{H} 5-\mathrm{H} 8)$ and findings indicate that $\mathrm{H} 5$, $\mathrm{H} 7$, and $\mathrm{H} 8$ are supported while $\mathrm{H} 6$ is not. For the latter hypothesis, this suggests that trust in internet is not influential to behavior intentions to use eHealth.

Results indicate that Performance Expectancy (PE) has a significant effect $(\beta=0.22, p<0.01)$ on behavioral intention to use. This suggests that consumers will use eHealth services if they believe it will increase their productivity or afford them some form of gain. In other words, the results mean that consumers have a high expectation of eHealth to satisfy their requirements.

An important research objective was to examine the link between PE and Trust in relation to behavioral intentions. Performance expectancy positively affects both trust of internet $(\beta=0.55, p<0.001)$ and trust of online healthcare providers $(\beta=0.39, p<0.001)$. Therefore, it can be said that performance expectancy affects behavioral intentions both directly and indirectly through trust in internet and trust in online healthcare providers (which is the most significant determinant of the behavioral intention to use). This emphasizes the significance of trust as a factor affecting consumers' decision to use eHealth.

Generally, among all the determinants, PE was a significant predictor of behavioral intentions through consumers' Tol $(\beta=0.55, \mathrm{p}<0.001)$ and ToH $(\beta=0.39, \mathrm{p}$ $<0.001)$ respectively. If the internet as a means through which one is to access eHealth services is slow, unreliable, and expensive it will be difficult to

Page 12/19 
encourage eHealth use. Likewise, if service providers are dishonest, insensitive and unscrupulous, engaging customers or maintaining those that exist is a difficult task (Bansal, 2016). This implies that PE indirectly influences behavioral intention since it affects Trust in online healthcare providers positively $(\beta=$ $0.10, \mathrm{p}<0.05)$.

Effort Expectancy $(E E)$ indicates statistical significance in relation to behavioral intention $(\beta=0.22, p<0.001)$. This implies that citizens will use eHealth services if they believe it to be easy to navigate and explore (Murathan Kurfali, 2017). This supports Stegwee's (2015) sentiments that difficulties in finding information due to vaguely structured menus and web pages means a waste of time and this is not what consumers want. Therefore, user-friendly and navigable structures should prioritized along with visual appeal (Stegwee, 2015).

Social influence (SI) was a significant factor determining behavioral intentions $(\beta=0.11, p<0.05)$. It can be deduced that consumers hold other peoples' opinions as an important factor influencing their decision to use eHealth services. People that are either important or influential to an individual such as colleagues, friends, parents, or other relatives play a key role in one's decision to use eHealth services.

Facilitating Conditions (FC) which is the existence of other conditions that consumers believe help them use eHealth services indicated a significant impact on behavioral intentions $(\beta=0.17, p<0.001)$. This implies that consumers acknowledge the significance of environmental factors that will facilitate use of eHealth services. Those with resources are more likely to use eHealth services unlike those that do not have the resources for it. Furthermore, those that have adequate knowledge are also inclined to use eHealth services in comparison with those lacking adequate knowledge.

Trust in Internet (Tol) showed an insignificant effect on behavioral intentions $(\beta=0.09, p<0.05)$. This implies that the level of trust individuals hold in the internet does not affect their decision to use eHealth services.

The significance of Trust in Online Healthcare Providers $(\mathrm{ToH}) \mathrm{H} 8(\beta=0.10, \mathrm{p}<0.05)$ is limited meaning that compared to Tol, consumers place importance on the role of online healthcare service providers in delivering relevant services. This in turn influences their decision to use eHealth services but is not a priority consideration.

\section{Conclusion}

The purpose of this study was to explore factors that influence eHealth adoption in Malawi. This was done using a variant of the UTAUT as the primary model incorporating trust of online healthcare providers and trust of internet as new constructs.

In this study, effort expectancy, performance expectancy, facilitating conditions, and social influence are influencing factors of consumer decision to use eHealth services. Similar studies have been conducted with few studies focusing on consumer adoption of eHealth services (Sorwar, 2017; Arif, 2014). Other studies in e-Government have proven that trust of internet and trust of government have an indirect positive effect on behavioral intentions through performance expectancy (Alsaghier, 2009; Carter and Belanger, 2005; Kurfali, 2017). However, this study explored the indirect effect of performance expectancy on behavioral intentions through trust in internet and trust in online healthcare providers.

Results may have profound importance to national policy-makers and other relevant stakeholders. Firstly, performance expectancy was highly significant meaning that in order to increase traffic to health websites, there is need to show the usefulness of the systems. Moreover, consumers expect to have a userfriendly system which will facilitate easy use of the eHealth system. This provides an opportunity for government to build reliable platforms for interaction with consumers with reference to health services and promote awareness about these facilities.

Furthermore, trust in online healthcare providers has a positive effect on behavioral intentions. It is therefore essential for online healthcare service providers to make sure their platforms are user-friendly and relevant to the needs of consumers. In addition, consumer trust in internet is not a significant factor for using eHealth services.

Results further show that facilitating conditions such as resources and knowledge are important factors for increasing use of eHealth. Thus, policy-makers ought to focus on providing necessary facilities to enable consumers to increase use and uptake of eHealth services. Lastly, social influences are important to consumer decision to use eHealth services. This in turn means that if one person decides to use eHealth services, many more in his/her social circle will be inclined to use eHealth. Paying close attention to findings of this study can facilitate greater adoption of eHealth in Malawi.

\subsection{Limitations and future direction}

Firstly, participant characteristics such as education level, occupation, and internet experience may vary from the whole population. Although it would be a daunting task, it would be worthwhile to conduct further studies with better representation of the whole population. For instance, the majority of those using the internet are employed. However, another relatively large group belongs to the "other" group of people which is only assumed to be students. Future research could focus on particular groups of those employed or focus on University students to further comprehend adoption behavior.

Secondly, the study employed purely quantitative measures to collect data. For instance, by borrowing the idea of (Hege K. Andreassen, 2007) in-depth studies through a combination of qualitative and quantitative measures to investigate what health information consumers are particularly interested in on the internet will provide useful insights into adoption behavior.

Thirdly, considering the economic status of the country and consequent economic characteristics of the population, a further look into a resource-based view or rather facilitating conditions may add valuable information on determinants of adoption.

Page 13/19 
Finally, the research data was collected from a developing country in which limitations and challenges relating to availability of and access to information on the use and applicability of technology in relation to health is limited as compared to the developed world. A similar study using data from developed countries would provide comparative insight on the generalizability of the results using these constructs.

\section{Declarations}

\section{Ethics approval and consent to participate}

Not applicable

\section{Consent for publication}

Not applicable

\section{Competing interests}

The datasets generated during the current study are available from the corresponding author on reasonable request.

\section{Funding}

The authors declare that they have no competing interests

\section{Authors' contributions}

AG came up with the study topic and wrote the first draft of the paper; KS analyzed data using Amos software; VEA revised the first draft to come up with the final version of the paper; MMU provided technical guidance in terms of conceptual framework and drafted the questionnaire; SL drafted the questionnaire and collected data

\section{Acknowledgements}

None

\section{References}

Ahern, D. K. (2007). Challenges and opportunities fo eHealth Research. American Journal of Preventive Medicine, 75-82.

Ahmad Alaiad, L. Z. (2014). An Exploratory Study of Home Healthcare Robots Adoption Applying the UTAUT Model. International Journal of Healthcare Information Systems and Informatics, 44-59.

Ahmad, B. I. (2014). User Acceptance of Health Information Technology in Developing Countries: A Conceptual Model. ResearchGate, 1-8.

Ahmad, M. I. (2015). Unified Theory of Acceptance and Use of Technology (UTAUT): A Decade of Validation and Development. ResearchGate, 1-14.

Arif, J. K. (2014). Investigating the behaviour intention to use e-health services by Swedish Immigrants. Örebro University, Swedish Business School, 1-22.

Aubert, R. F. (2015). Citizenship, trust, and behavioural intentions to use public e-services: The case of Lebanon. International Journal of Information Management, 1-6.

Authority, N. E.-H. (2016, 04 21). Evolution of E-health in Australia: Achievements, lessons, and opportunities. Retrieved from www.digitalhealth.gov: https://www.digitalhealth.gov.au/about-the-agency/publications/reports/benefit-and-evaluation-reports/evolution-of-ehealth-in-australia-achievementslessons-and-opportunities/Evolution\%20of\%20eHealth\%20in\%20Australia_Publication_20160517.pdf

Bansal, N. G. (2016). Application of Decomposed Theory of Planned Behaviour for M-Commerce Adoption in India. In Proceedings of the 18th International Conference on Enterprise Information Systems (ICEIS 2016) (pp. 357-367). Kanpur: Science and Technology Publications.

Bechger, J. H. (2003). An introduction to Structural Equation Modeling. Family Science Reveiw, 354-373.

Belanger, L. C. (2005). The utilization of e-Government services: Citizen trust, innovation and acceptance factors. Information Systems Journal, 5-25.

Bichler, R. M. (2008). Information and Communication Technologies in the Republic of Malawi: An Assessment of Progress and Challenges Ahead. Towards an ICT Research Agenda for African Development (pp. 189-202). Pretoria: University of Pretoria. 
Binesh Sarwar, S. Z. (2018). Usage of Social Media Tools for Collaborative Learning: The Effect on Learning Success With the Moderating Role of Cyberbullying. Journal of Educational Computing, 1-34.

Calvin K. L. Or, B.-T. K. (2011). Factors affecting home care patients' acceptance of a web-based interactive self-management technology. Journal of the American Medical Informatics Association, 51-59.

Caroline Lancelot Miltgen, A. P. (2013). Determinants of end-user acceptance of biometrics: Integrating the "Big 3" of technology acceptance with privacy context. . Pubmed, 103-114.

Carter, L. C. (2010). The impact of trust, risk and optimism bias on E-file adoption. Information Systems Frontiers, 299-309.

Chikumba, P. A. (2017). Management of Health Information in Malawi: Role of Technology. Advances in Science, Technology and Engineering Systems Journal, 157-166.

Cooper/Smith, M. o. (2018, 05 01). mHealth in Malawi: Landscape Analysis. Retrieved from www.static1.squarespace.com:

https://static1.squarespace.com/static/548487dce4b08bf981fe60d5/t/5b18fb5f6d2a73891c7a2a1f/1528363963131/FINAL_malawi_mhealth_landscape_ar

D.M. Rousseau, S. S. (1998). Not So Different Afterall: A Cross-Discipline View of Trust. Academy of Management Review, 393-404.

David F. Lobach, \&. D. (2007). Research Challenges for Electronic Health Records. American Journal of Preventive Medicine, $104-111$.

Dessel, G. V. (2013, 02 01). How to determine population and survey sample size. Retrieved from https://www.checkmarket.com:

https://www.checkmarket.com/blog/how-to-estimate-your-population-and-survey-sample-size/

eVisit. $(2018,10$ 10). What is the Difference between telehealth, telecare and telemedicine. Retrieved from eVisit: https://evisit.com/resources/what-is-thedifference-between-telemedicine-telecare-and-telehealth/

Eysenbach, G. (2001). What is E-health. Journal of Medical Internet Research, 1-2.

Fletcher, A. (2018, 06 01). What's APPening in Malawi? An overview of the National mHealth Landscape Analysi. Retrieved from www.coopersmith.com: https://coopersmith.org/blog/2018/6/26/whats-appening-in-malawi-an-overview-of-the-national-mhealth-landscape-analysis

Gunawardena, G. D. (2014). Comparison of Existing Technology Acceptance Theories and Models to Suggest a Well Improved Theory/Model. International Technical Sciences Journal (ITSJ), 21-36.

310. Alsaghier, M. F. (2009). Conceptualizing Citizen's Trust in e-Government: Application of Q Methodology. Electronic Journal of eGovernment, $295-310$.

Hans Oh, C. R. (2005). What is eHealth? A Systematic Review of Published Definitions. Pubmed, 32-40.

Health, M. o. (2014). The Malawi National eHealth Strategy. Lilongwe: Ministry of Health.

Healy, D. J.-C. (2008, 01 01). Implementing e-Health in Developing Countries: Guidance and Principles. Retrieved from www.itu.int: http:www.itu.int/ITUD/cyb/app/docs/e-Health_prefinal_15092008.PDF

Hege K. Andreassen, M. M.-F. (2007). European citizens' use of E-Health services: A Study of Seven Countries. BioMed Central, 1-7.

Joana Urbano, A. P. (2012, 11 28). A Socio-cognitive Perspective of Trust. Retrieved from www.paginas.fe.up.pt:

https://paginas.fe.up.pt/ niadr/PUBLICATIONS/2013/Ch23_A_Socio-cognitive_Perpective_of_Trust.pdf

John C. Fortney, J. F. (2011). A reconceptualization of Access for 21st Century Healthcare. Journal of General Internal Medicine, 1-9.

John M. Blythe, L. S. (2017). The role of trust in eHealth websites: the enduring power of impartiality. 3rd UCL Centre for Behaviour Change Digital Health Conference 2017: Harnessing digital technology for behaviour change. London. Retrieved from https://www.frontiersin.org:

https://www.frontiersin.org/10.3389/conf.FPUBH.2017.03.00056/event_abstract

John, S. (2012). How online trust influence B2C e-Commerce. Association for Information Systems, 1-13.

Jolly, D. R. (2011, 11 17). The eHealth Revolution-Easier Said than Done. Retrieved from www.aph.gov.au:

https://www.aph.gov.au/about_parliament/parliamentary_departments/parliamentary_library/pubs/rp/rp1112/12rp03

Jorge Tavares, A. G. (2018). Electronic Health Record Portals adoption: Empirical model based on UTAUT2. Informatics for health \& social care, 109-125.

Kamkarian, P. (2016, 05 23). A Brief History of IT. Retrieved from www.ehs.siu.edu: https://ehs.siu.edu/_common/documents/IT\%20newsletter/vol-2-no-29.pdf

Kankuzi, B. (2008, 12 16). A Decade of the Internet in Malawi. Retrieved from www.bkankuzi.blogspot.com: http://bkankuzi.blogspot.com/2008/12/decade-ofinternet-in-malawi.html

Katalin, F. (2016, 01 01). The Social Theory of Trust and the Sociological Theory of Social Capital. Retrieved from http://www.belvedere-meridionale.hu: http://www.belvedere-meridionale.hu/wp-content/uploads/2016/01/09_Fuzer_BelvedereMeridionale_vol28_2016_01.pdf

Page $15 / 19$ 
Kebede, D. (2014, 09 04). Leveraging eHealth to improve national health systems in the African region. Retrieved from www.aho.afro.who.int: http://www.aho.afro.who.int/sites/default/files/ahm/reports/47/ahm-issue-14-leveraging-ehealth.pdf

Khamula, O. (2017, 02 15). Malawi Parliament raises child age definition from 14 to 18 years: Illegal to marry a girl before 18. Retrieved from www.nyasatimes.com: https://www.nyasatimes.com/malawi-parliament-raise-child-age-definition-14-18-years-illegal-marry-girl-18/

Khwima E. Mkalira Msiska, A. K. (2017). Factors affecting the utilisation of electronic medical records system in Malawian central hospital. Malawi Medical Journal, 1-10.

Kripanont, N. (2007, 01 06). Using Technology Acceptance Model of Internet Usage by Academics within Thai Business Schools. Retrieved from Victoria University: http://wallaby.vu.edu.au/adt-VVUT/public/adt-VVUT20070911.152902/index.html

Lai, P. (2017). The Literature Review of Technology Adoption Models and Theories for the Novelty Technology. Journal of Information Systems and Technology Management, 21-38.

Lankton, E. V. (2004). Modeling Patients' Acceptance of Provider-delivered eHealth. Journal of the American Medical Informatics Association, $241-248$.

Laurian C. Vega, E. M. (2011). Trust between patients and health websites: a review of the literature and derived outcomes for empirical studies. National Institute of Health, 1-18.

Malawi, G. o. (2014, 01 01). Malawi National E-Health Strategy. Retrieved from World Health Organization:

www.who.int/goe/policies/malawi_ehealth_strategy2011_2016.pdf

Malawi, G. o. (2015). Malawi National Health Information System Policy. Lilongwe: Government, Malawi.

Malawi, G. o. (2017, 07 19). Health Sector Strategic Plan Il: 2017-2022. Retrieved from www.health.gov.mw: www.health.gov.mw/index.php/policiesstrategies?download=47:hssp-ii-final

Mark Tomlinson, M. J.-B. (2013, 02 12). Scaling Up mHealth: Where Is the Evidence? Retrieved from https://journals.plos.org: https://journals.plos.org/plosmedicine/article?id=10.1371/journal.pmed.1001382

Martin R. Cowie, J. I. (2016). Electronic health records to facilitate clinical research. Springer, 1-9.

Milos Maryska, P. D. (2012). The Importance of ICT Sector and ICT University Education for the Economic Development. Procedia-Social and Behavioural Sciences, 1060-1068.

Mohammed Alshehri, S. D. (2013). Analysis of Citizens' Acceptance for E-Government Services: Applying the UTAU Model. ResearchGate, 1-9.

Molefi, M. (2010, 03 01). An Assessment of e-Health Projects and Initiatives in Africa. Retrieved from www.assets.publishing.service.gov.uk: https://assets.publishing.service.gov.uk/media/57a08af640f0b652dd0009e8/Assessment_of_eHealth_Africa.pdf

Morris, A. D. (2001). User Acceptance of Information Technology. London: Taylor \& Francis.

Murathan Kurfali, A. A. (2017). Adoption of e-Government services in Turkey. Computers in Human Behaviour, 168-178.

Murray, R. O. (2000, 2 23). What is knowledge Management. Retrieved from www.providersedge.com: http://www.providersedge.com/docs/km_articles/what_is_knowledge_management.pdf

Nkuzi, D. M. (2014). Determinants of Electronic Health in Developing Countries. International Journal of Arts and Commerce, 49-61.

Office, M. N. (2018, 12 01). 2018 Malawi Population and Housing Census preliminary report. Retrieved from www.nsomalawi.mw:

http://www.nsomalawi.mw/images/stories/data_on_line/demography/census_2018/2018\%20Population\%20and\%20Housing\%20Census\%20Preliminary\%20

Organization, W. H. (2012, 01 01). Global Diffusion of eHealth. Retrieved from www.who.int:

http://apps.who.int/iris/bitstream/handle/10665/252529/9789241511780-eng.pdf?sequence=1

Organization, W. H. (2015, 01 01). Atlas of eHealth Country Profiles. Retrieved from www.who.int:

http://apps.who.int/iris/bitstream/handle/10665/204523/9789241565219_eng.pdf?sequence=1

Organization, W. H. (2018, 02 01). Global Observatory for eHealth. Retrieved from https://www.who.int: https://www.who.int/goe/en/

Pavlou, P. A. (2003). Consumer Acceptance of Electronic Commerce: Integrating Trust and Risk with the Technology Acceptance Model. International Journal of Electronic Commerce, 69-103.

Philip J. Nickel, M. F. (2010, 09 07). Can We Make Sense of the Notion of Trustworthy Technology. Knowl Tech n Pol, pp. $429-444$.

Pradeep Paul George, N. P.-S. (2014). Online eLearning for undergraduate in health professions: A systematic review of the impact on knowledge, skills, attitudes, and satisfaction. Journal of Global Health, 1-10. 
Pulidindi Venugopal, S. J. (2016). User Acceptance of Electronic Health Records: Cross Validation of UTAUT model. Sona Global Management Review, 1-13. Quandt, A. K. (2016, 01 01). Relational Trust and Distrust: Ingredients of Face-to-Face and Media-Based Communication. Retrieved from www.springer.com: file:///C:/Users/HP/Downloads/9783319280578-c1.pdf

Roger C. Mayer, J. H. (1995). An Integrative Model of Organizational Trust. Academy of Management, 709-734.

Rouse, M. (2018, 01 01). Definition: Digital Divide. Retrieved from https://whatis.techtarget.com: https://whatis.techtarget.com/definition/digital-divide Sandberg, G. E. (2016). eHealth Opportunities and Challenges: A White Paper. Lund: Lund Univeristy.

Sekaran, U. (2003). Research Methods for Business: A Skill-Building Approach. 4th Edition. New York: John Wiley \& Sons.

Services, U. D. (2006). Expanding the Reach and Impact of Consumer eHealth Tools. Office of Disease Prevention and Health Promotion.

Shalini Chandra, S. C.-L. (2010, 10 01). Evaluating the Role of Trust in Consumer Adoption of Mobile Payment Systems: An Empirical Analysis. Communications of the Association for Information Systems, pp. 1-30.

Simpson, J. A. (2007, 07 01). Psychological Foundations of Trust. Retrieved from https://apps.cla.umn.edu: file:///C:/Users/HP/Downloads/Simpson_Current_Directions_2007_.pdf

Skidmore, H. T. (2014, 05 01). Do Natural Distasters enhance Societal Trust. Retrieved from www.sci-hub.tw: http://scihub.tw/https://doi.org/10.1111/kykl.12053

Sorwar, R. H. (2017). Understanding factors influencing the adoption of mHealth by the elderly: An extension of the UTAUT model. International Journal of Medical Information, 75-84.

Stats, I. W. (2018, 01 01). Internet Usage and Population Statistics for Africa. Retrieved 06 06, 2018, from internetworldstats:

https://www.internetworldstats.com/africa.htm\#mw

Stegwee, M. E. (2015, 01 01). Trust in eHealth Services: A Practice Driven Review of the Literature. Retrieved from ResearchGate:

https://www.researchgate.net/publication/303938474

Sullivan, F. (2001). What is Health Informatics. Journal of Health Services Research \& Policy, 251-254.

Taylor, M. J. (2013, 01 01). Profiling eHealth projects in Africa: Trends and Funding Patterns. SagePub, 1-20. Retrieved from sagepub.

Theon, Y. T. (2001). Towards a generic model of trust for electronic commerce. International Journal of Electrponic Commerce, 61-74.

Thomas J. Madden, P. S. (2014). A Comparison of Theory of Planned Behaviour and theory of Reasoned Action. Sage Social Science Collections, 1-8.

Tomlinson, E. C. (2009). The Role of Causal Attribution Dimensions in Trust Repair. Academy of Management Review, 85-104.

UCA. (2018, 11 25). Sampling Techniques. Retrieved from http://uca.edu: http://uca.edu/psychology/files/2013/08/Ch7-Sampling-Techniques.pdf

Union, I. T. (2008). Implementing e-Health in Developing Countries: Guidance and Principles. Geneva: International Telecommunication Union.

Union, I. T. (2018, 01 01). The ICT Development Index (IDI): Conceptual Framework and Methodology. Retrieved from www.itu.int: https://www.itu.int/en/ITUD/Statistics/Pages/publications/mis2017/methodology.aspx

Unit, I. T. (2008, 09 01). Implementing eHealth in Developing Countries. Retrieved from www.itu.int: https://www.itu.int/ITU-D/cyb/app/docs/eHealth_prefinal_15092008.PDF

Venkatesh, V. (2013). Theory of Acceptance and Use of Technology: A Synthesis and Road Ahead. Journal of the Association for Information Systems, 328376.

Venkatesh, V., Morris, M. G., Davis, G. B., \& Davis, a. F. (2003). User Acceptance of Information Technology: Toward a Unified View. Management Information Systems Quarterly, 425-478.

Wallace, K. C. (2003). Trust in Electronic Environments. Proceedings of the 36th Hawaii International Conference on System Sciences (pp. 1-11). Honolulu: ResearchGate.

Wass, S. (2017). The Importance of eHealth Innovations. Jonkoping: Jonkoping International Business School.

Weiser, E. B. (2002). The Functions of Internet Use and their Social and Psychological Consequences. CyberPsychology and Behaviour, $723-743$.

Weitzl, W. (2017, 01 01). Review of Literature \& Theoretical Background: The Role of Trust. Retrieved from www.springer.com:

file:///C:/Users/HP/Downloads/9783658158880-c2.pdf

Page $17 / 19$ 
Wesley Shrum, K. R. (2007). Past, Present and Future of Research in the Information Society. New York: Springer Science +Business Media, LLC.

Wilson-Evered, T. C. (2012). Predicting uptake of technology innovations in online family dispute resolution services: An application and extension of the UTAUT. Computers in Human Behavior, 2034-2045.

Zach Landis-Lewis, R. M. (2015). Barriers to using eHealth data for clinical performance feedback in Malawi: A Case Study. International Journal of Medical Informatics, 868-875.

\section{Table 1}

Table 1: Hypotheses

\begin{tabular}{|l|l|}
\hline Number & Hypothesis \\
\hline H1 & Performance expectancy will positively affect behavioral intention to use e-health services \\
\hline H2 & Effort expectancy will positively affect behavioral intentions to use e-health services \\
\hline H3 & Social Influence will positively affect behavioral intentions to use e-health services \\
\hline H4 & Facilitating conditions will positively affect behavioral intentions to use e-health services \\
\hline H5 & performance expectancy will positively affect Trust of internet \\
\hline H6 & Trust of internet will positively affect behavioral intentions to use e-health services \\
\hline H7 & Performance expectancy will positively affect Trust of online e-health service providers \\
\hline H8 & Trust of online e-health service providers will positively affect behavioral intentions to use e-health services \\
\hline
\end{tabular}

\section{Figures}

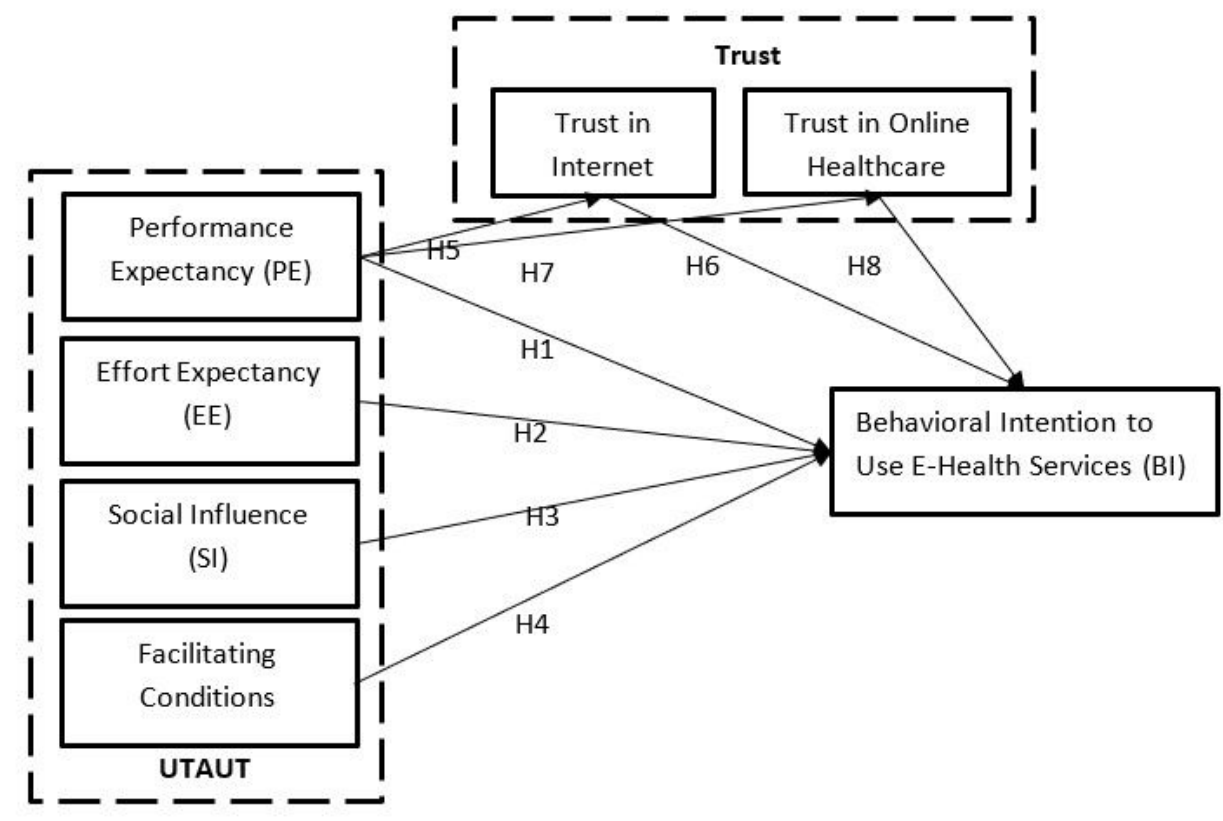

Figure 1

Proposed research model 

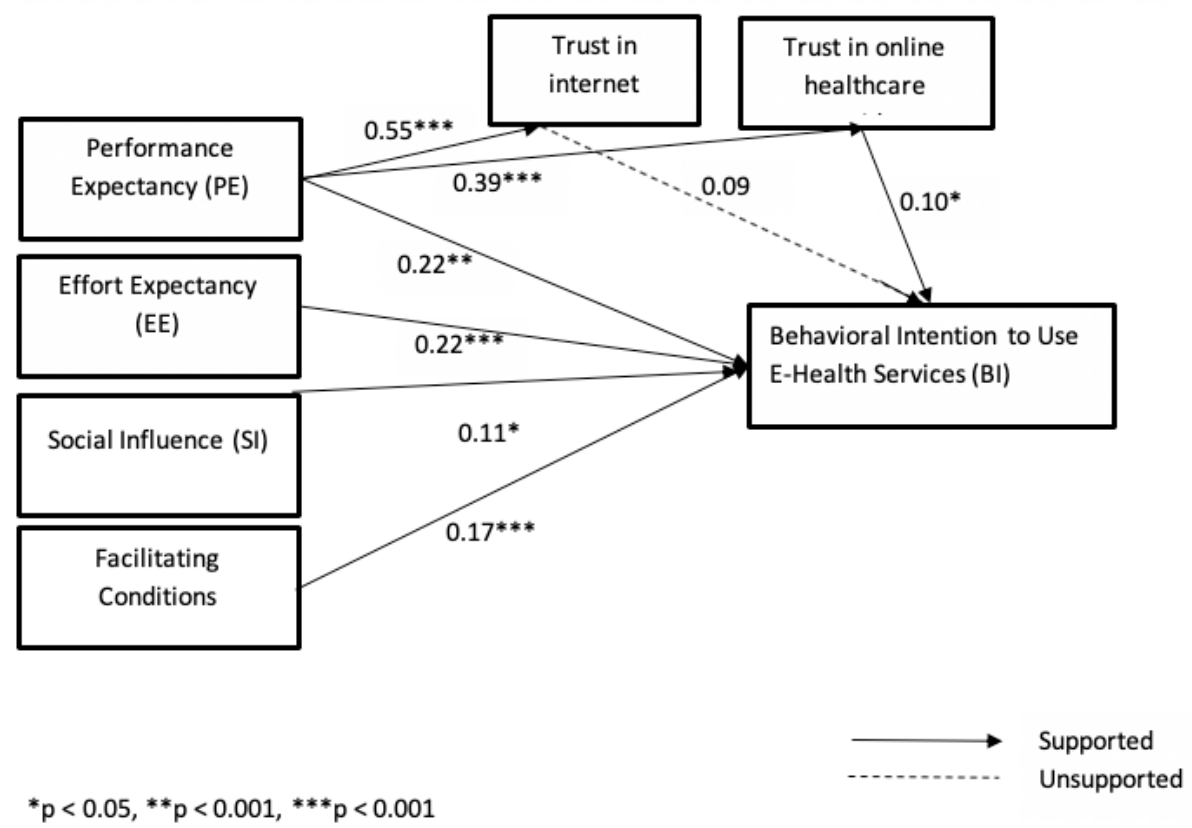

Figure 2

Results of hypothesis testing

\section{Supplementary Files}

This is a list of supplementary files associated with this preprint. Click to download.

- SupTable.docx 